\title{
An unusual tracheal tumour
}

Fabien Rolland MD, Francis Laberge MD FRCPC, Antoine Delage MD FRCPC

\section{CASE PRESENTATION}

A 63-year-old man was referred to the authors' centre for an anomaly discovered on routine preoperative chest radiograph. He was a former smoker with known metabolic syndrome and presented with no respiratory symptoms. A lateral chest radiograph revealed a round opacity in the mid-trachea (Figure 1). On computed tomography (CT) of the thorax, a $15 \mathrm{~mm}$ endotracheal nodule obstructing the middle one-third of the trachea was noted (Figure 2). The nodule had an average density of -126 Hounsfield units (HU), compatible with a high-fat tumoural content. This was suggestive of a benign diagnosis such as a lipoma or hamartoma. Bronchoscopy confirmed the presence of a pedunculated tumour originating from the lateral wall of the midtrachea and obstructing approximately $60 \%$ of its lumen (Figure 3 ). The tumour was succesfully removed via flexible bronchoscopy using an electrocautery snare (Figure 4). Subsequent pathological examination confirmed a diagnosis of endobronchial lipoma. No signs of relapse and normal tracheal patency were observed on control bronchoscopy performed six months after resection.

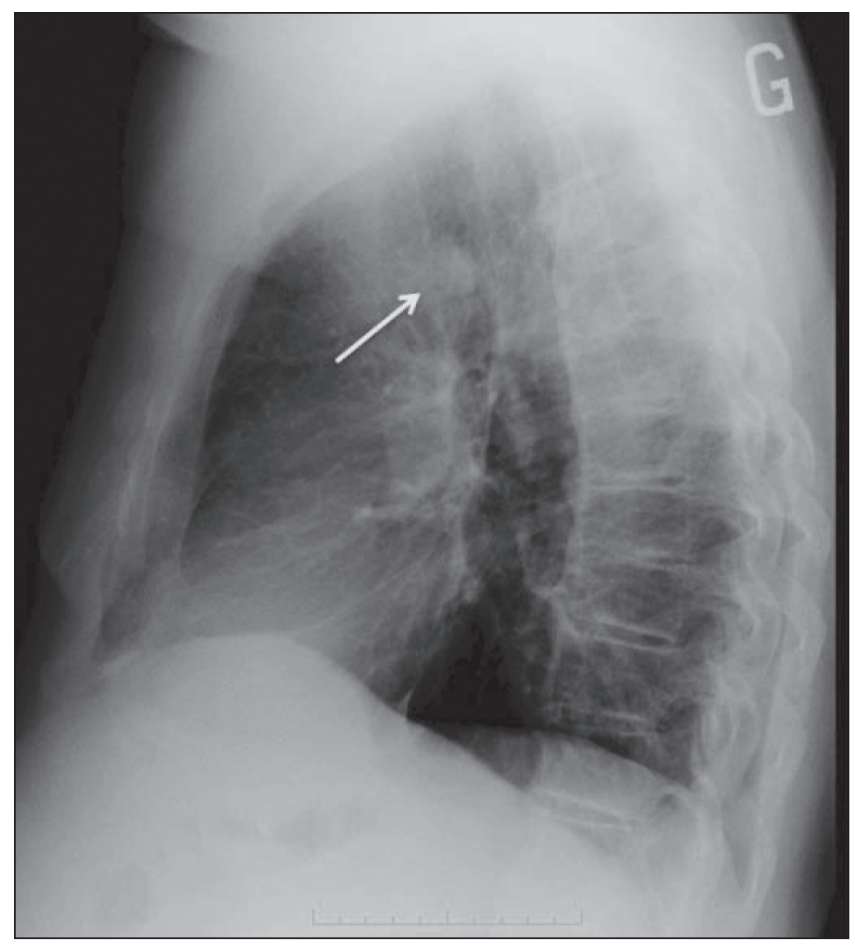

Figure 1) Lateral chest $x$-ray showing a rounded opacity overlapping the mid-trachea

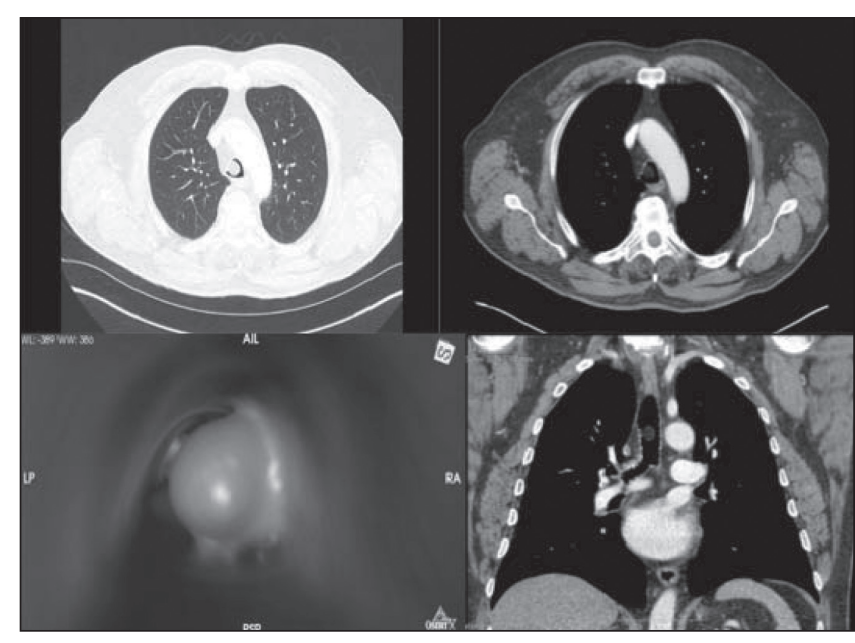

Figure 2) Chest computed tomography with three-dimensional reconstruction of the trachea showing a $15 \mathrm{~mm}$ pedunculated nodule originating from the right lateral wall of the mid-trachea. The nodule density was -126 Hounsfield units, indicating the presence of fat and suggesting a benign etiology

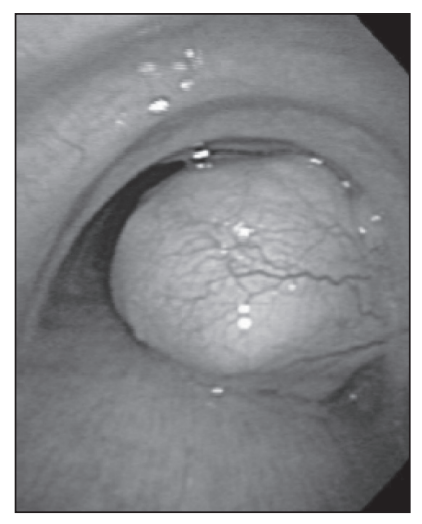

Figure 3) Bronchoscopy showing a smooth, poorly vascularized, pedunculated tumour in the mid-trachea

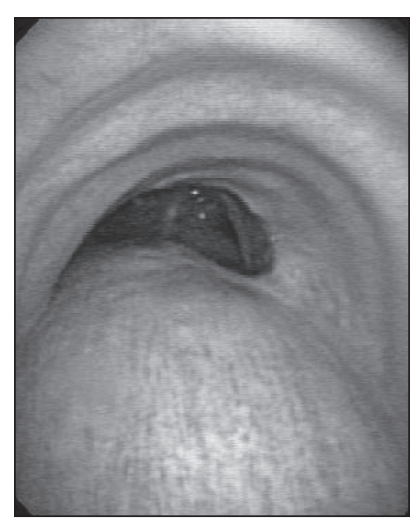

Figure 4) Photograph of the trachea after endoscopic resection of the tumour using snare electrocautery. Pathological analysis confirmed a diagnosis of tracheal lipoma

Département multidisciplinaire de pneumologie et chirurgie thoracique, Institut universitaire de cardiologie et de pneumologie de Québec, Université Laval, Québec, Québec

Correspondence: Dr Antoine Delage, Département multidisciplinaire de pneumologie et chirurgie thoracique, Institut universitaire de cardiologie et de pneumologie de Québec, 2725 chemin Ste-Foy, Québec, Québec G1V 4G5. Telephone 418-656-8711, fax 418-656-4762,

e-mail antoine.delage@criucpq.ulaval.ca 


\section{KEY LEARNING POINTS}

- Tracheal tumours are the least common major airway tumours. More than $80 \%$ are malignant in origin. Squamous cell carcinoma and adenoid kystic carcinoma are the most frequent types of tracheal tumours. The most common benign tracheal tumours are hamartomas, papillomas and amyloid tumours. Lipomas account for $2 \%$ to $4 \%$ of benign tracheal tumours (1).

- The trachea has a large physiological reserve and subjects will often remain asymptomatic until luminal obstruction exceeds $70 \%$.

- HU are a measure of CT tissue attenuation. Water has a density of $0 \mathrm{HU}$, whereas the density of soft tissues usually ranges from $40 \mathrm{HU}$ to $80 \mathrm{HU}$ and that of fat from $-60 \mathrm{HU}$ to $-100 \mathrm{HU}$.

\section{REFERENCES}

1. Shah H, Garbe L, Nussbaum E, Dumon JF, Chiodera PL, Cavaliere S. Benign tumors of the tracheobronchial tree. Endoscopic characteristics and role of laser resection. Chest 1995; 107:1744-51.
Average nodule density below $-100 \mathrm{HU}$ on CT indicates a high fat content and is highly suggestive of a lipomatous tumour. However, CT or magnetic resonance imaging alone cannot exclude malignancy, and pathological examination is necessary (2).

- Management of benign endobronchial tumours is usually surgical. Endoscopic resection is considered to be appropriate in selected cases such as tumours with no evidence of airway wall extension, pedunculated tumours, tumours with a low risk of relapse or in subjects whose medical comorbidities would preclude surgical resection (3). In the present case, because the tumour was pedunculated and likely benign in origin, removal was performed under general anesthesia using flexible bronchoscopy with snare electrocautery.

2. Kuhlman JE, Bouchardy L, Fishman EK, Zerhouni EA. CT and MR imaging evaluation of chest wall disorders. Radiographics 1994;14:571-95.

3. Gao H, Ding X, Wei D, et al. Endoscopic management of benign tracheobronchial tumors. J Thorac Dis 2011;3:255-61. 


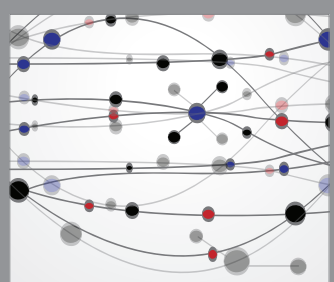

The Scientific World Journal
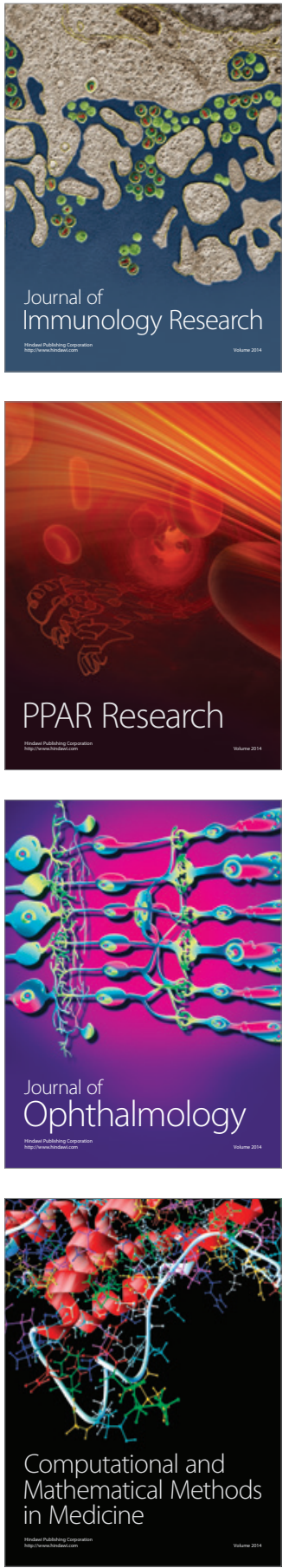

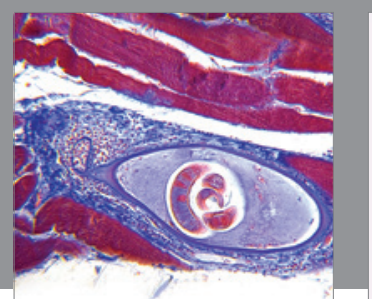

Gastroenterology Research and Practice

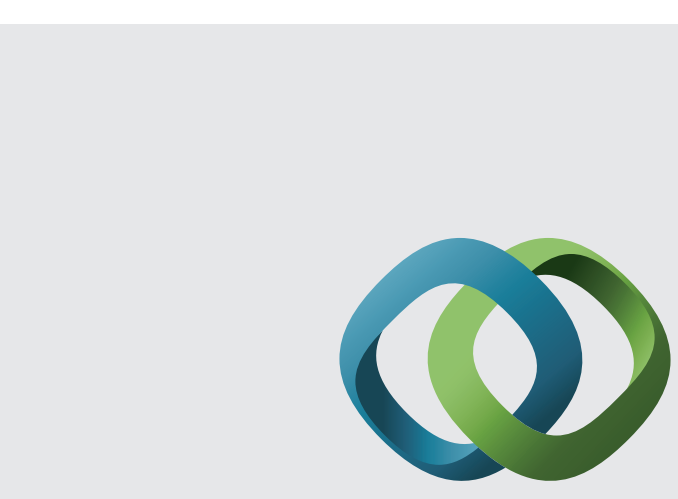

\section{Hindawi}

Submit your manuscripts at

http://www.hindawi.com
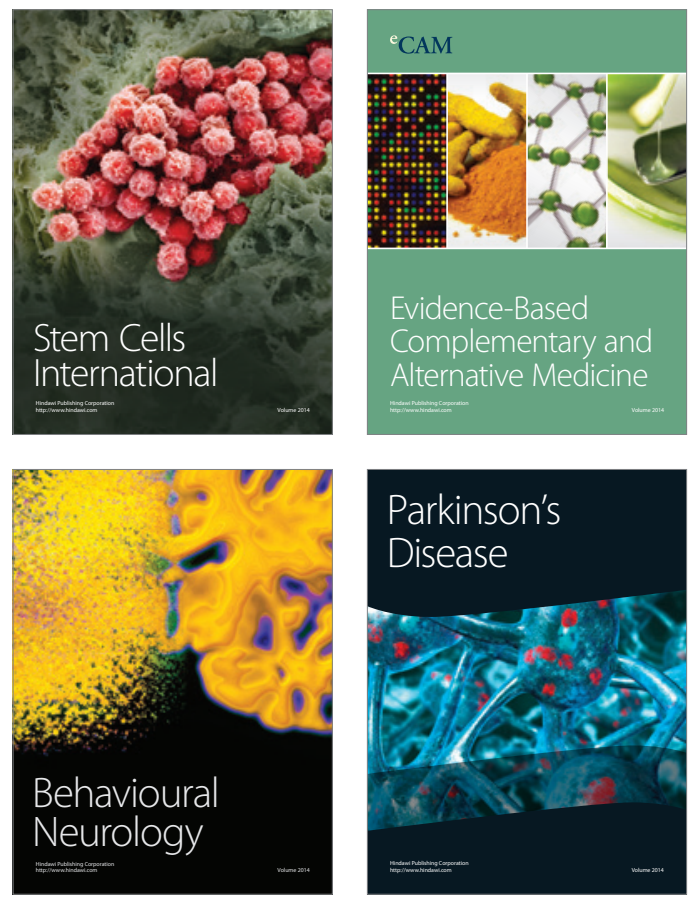
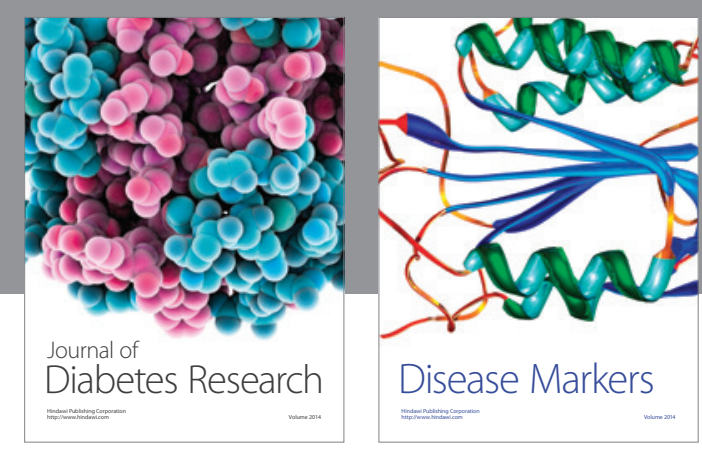

Disease Markers
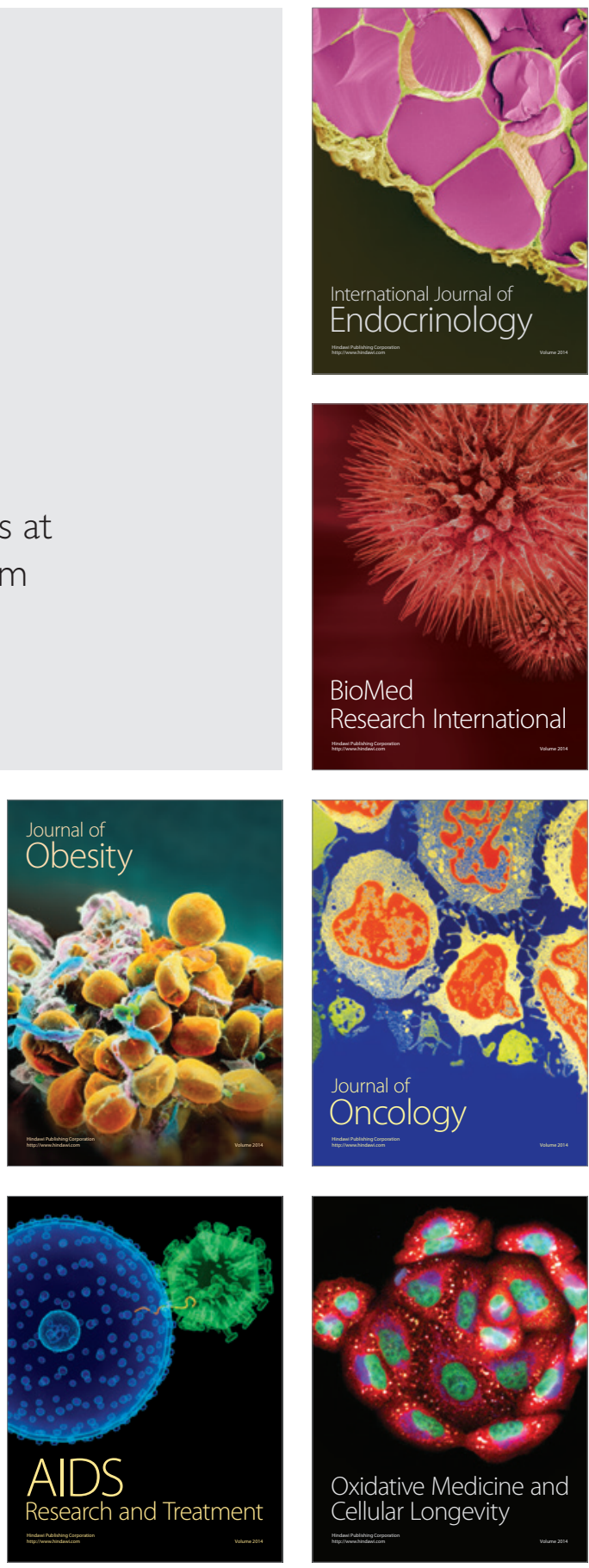